\title{
Synthesis and characterization of a novel extra large pore aluminophosphate molecular sieve, NCL-6
}

\author{
N. Venkatathri \\ Catalysis Division, National Chemical Laboratory, Pune-411 008, India \\ E-mail : venkat@cata.ncl.res.in_Fax:91-20-5893761 \\ Manuscript received 10 July 2003, revised 12 April 2004, accepted 30 August 2004
}

\begin{abstract}
A novel extra large pore aluminophosphate molecular sieve NCL-6, has been prepared and characterized by various techniques such as XRD, SEM, TG/DTA, carbon and nitrogen analysis, FT-IR and MAS NMR are reported. X-Ray diffraction pattern shows that the synthesized sample is crystalline and have novel structure. SEM analysis indicate the phase purity and having granules morphology with $3 \times 5 \mu \mathrm{m}$ particle size. FT-IR spectrum in the framework region shows that the sample is similar to the other known aluminophosphates. TG/DTA shows that the sample losses $30.45 \%$ due to the loss of water and organic molecules. Aluminium and phosphorous NMR shows that the presence of four different aluminium and three different phosphorous sites. The NMR are similar to VPI-5, NCL-2 and NCL-3.
\end{abstract}

Since the first discovery of zeolite, numerous natural and synthetic zeolites ${ }^{1,2}$, silica polymorphs, aluminophosphatebased molecular sieves ${ }^{3,4}$, and microporous compounds built from $\mathrm{MO}_{4}$ tetrahedra (where $\mathrm{M}$ is neither aluminium nor silicon, e.g. gallophosphate microporous crystals ${ }^{5,6}$ ) have been brought to light. These materials are prepared hydrothermally, and some of them possess new framework structures. VPI- $5^{7}$, for example, is an extra-large ring aluminophosphate microporous material consisting of 18 tetrahedral (18T) atoms. Recently, a synthetic gallophosphate molecular sieve with a $20 \mathrm{~T}$ atom pore opening, cloverite ${ }^{8}$, was reported. This is the largest ring among the natural and synthetic zeolite and zeolite-like materials. More recently, a microporous crystalline material possessing 20T-atom channel, designated as JDF- $20^{9}$, was synthesized. This material has aluminophosphate composition whose channel is circumscribed with $20 \mathrm{~T}$-atoms. We report here the synthetic procedures used to crystallize NCL-6, and some of the relevant characterization data on NCL-6.

\section{Results and discussion}

Peak positions of X-ray powder diffraction pattern of the NCL- 6 so synthesized do not fit to the any of the reported pattern ${ }^{10,11}$. The first peak at $17.31 \mathrm{~d}$ vallie shows that the synthesized molecular sieve is a extra large pore sized. This pattern is stable upto $250^{\circ} \mathrm{C}$. Elemental analysis of calcined sample shows the composition is $\mathrm{Al}_{2} \mathrm{O}_{3} ; 0.99$ $\mathrm{P}_{2} \mathrm{O}_{5}$. Scanning electron microscopy (SEM) shows that the NCL-6 exists as granules with particle size $3 \times 5 \mu \mathrm{m}$, and also indicates that the product is pure. The IR spectrum shows three bands at 1176.5-1080, 880-757 and 544.9$\begin{array}{llll}4 & 9 & 5 & 7\end{array}$ $\mathrm{cm}^{-1}$ which are characteristic of aluminophosphate molecular sieves. The asymmetric stretching vibrations of the P-O-Al unit occur at 1176.5 and 1080.1 and symmetric stretching vibration of $\mathrm{P}-\mathrm{O}-\mathrm{Al}$ is at 880 and $757.0 \mathrm{~cm}^{-1}$. The band $544.9 \mathrm{~cm}^{-1}$ is due to double ring vibrations and the peak at $495.7 \mathrm{~cm}^{-1}$ is due to P-O-Al bending vibrations. These are characteristic vibrations of the aluminophosphate framework. The NCL- 6 sample was subjected to thermal analysis on a differential thermal analysis (DTA) instrument under a flow of $\mathrm{N}_{2}$ at a rate of $10^{\circ} \mathrm{C} \mathrm{min}^{-1}$ (Fig. 1). Thermogravimetric analysis indicated losses of $30.45 \% \mathrm{~m} / \mathrm{m}$ from 25 to $575^{\circ} \mathrm{C}$. This mass loss corresponds to the amount of organic molecules and water adsorbed by NCL- 6 . The

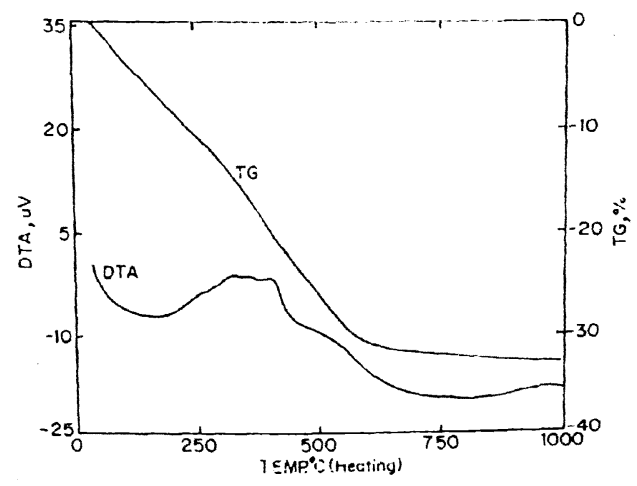

Fig. 1. TG (a)/ DTA (b) analysis of NCL-6. 


\section{J. Indian Chem. Soc., Vol. 82, January 2005}

exothennic peaks at $405^{\circ} \mathrm{C}\left(298-462^{\circ} \mathrm{C}\right)$ and $570^{\circ} \mathrm{C}(462-$ $692^{\circ} \mathrm{C}$ ) gives weight loss 10.87 and $3.70 \%$ respectively are due to the oxidative decomposition of the template molecules. The higher temperature to eliminate the organic molecules indicate the strong interaction of template molecules with the aluminophosphate framework. Carbon and nitrogen analysis indicate the content are $\mathrm{C}=15.93$ and $\mathrm{N}$ $=2.55 \%$.

The ${ }^{27}$ AI MAS NMR spectra of the synthesized NCL-6 shows resonances at $\delta 44.6,37.5,-4.8$ and -21.7 is similar to NCL-2 except octahedrally co-ordinated aluminium at $\delta$ $-4.8^{12}$. Remaining peaks are due to aluminium in tetrahedral co-ordination. The ${ }^{31} \mathrm{P}$ MAS NMR spectrum of NCL6 (two sharp resonance at $\delta-24.2,-28.8$ and a diffuse peak at -34.6$)$ is rather similar to VPI-5 $(\delta-23.3,-33.1$ and $-27.12)$, NCL-2 $(\delta-26.6,-30.4$ and -37.22$)$ and NCL-3 $(\delta$ $-15.63,-23.26$ and -27.88$)^{13}$. The first two peaks are due to tetrahedrally co-ordinated phosphorous atoms and third one is due to octahedrally co-ordinated phosphorous atoms.

\section{Conclusion:}

A novel extra large pore aluminophosphate molecular sieve NCL- 6 was synthesized and characterized by various physicochemical techniques such as XRD, SEM, TG/DTA, FT-IR and MAS NMR. X-Ray diffraction analysis shows that the sample is novel, pure and highly crystalline. SEM photograph shows that the sample is pure and having granules morphology with particle size $3 \times 5 \mu \mathrm{m}$. FT-IR spectrum in framework region shows that the sample is similar to the other known aluminophosphates. TG/DTA shows that the sample losses $30.45 \%$ of the total weight due to the loss of adsorbed template and water molecules. There are two stages of oxidative decomposition occur in the sample. The ${ }^{27} \mathrm{Al}$ and ${ }^{31} \mathrm{P}$ MAS NMR shows the presence four types of aluminium and three types of phosphorous sites. The spectra is similar to VPI-5 and NCL-2 and NCL-3.

\section{Experimental}

NCL-6 was synthesized in the presence of template hexamethyleneimine (HEM, 98\%, Aldrich, USA) from a predominantly non-aqueous system using ethylene glycol (EG, 99\%, s.d. fine, India) as the solvent. Aluminium triisopropoxide ( $98 \%$, Aldrich, USA) and phosphoric acid $\left(85 \% \mathrm{H}_{3} \mathrm{PO}_{4}\right)$ were used exclusively as the aluminium and phosphorous starting materials, respectively. A typical synthesis procedure involves the following steps : (i) aluminium triisopropoxide $(6.05 \mathrm{~g})$ is slurried in solvent, ethyleneglycol $(45.50 \mathrm{~g})$, (ii) hexamethyleneimine $(7.24 \mathrm{~g})$ is added to the aluminous slurry, (iii) the phosphoric acid $(6.024 \mathrm{~g})$ added dropwise to the mixture, (iv) the whole mixture is stirred until it becomes homogeneous ( $24 \mathrm{~h}$ ) forming the final gel having molar composition $\mathrm{Al}_{2} \mathrm{O}_{3}: 1.8 \mathrm{P}_{2} \mathrm{O}_{5}: 4.5 \mathrm{HEM}$ :
45 EG which (v) is charged into a Parr reactor and heated at $473 \mathrm{~K}$ for 15 days with stirring, the autoclave is removed from the reactor, and allowed to cool and products recovered by filteration with copious amounts of water or another solvent and dried in ambient air.

$X$-Ray diffraction patterns were recorded on a Rigaku (D/MAX III VC) instrument in the $2 \theta$ region of $5-45^{\circ}$. Scanning electron microscope pictures were taken using a JEOL JSM 5200 microscope : Chemical analysis was carried out by XRF using a Rigaku $3070 \mathrm{X}$-ray spectrometer. Carbon and nitrogen were estimated by microanalysis. The framework IR spectra were recorded in the diffuse reflectance mode using 300: 1 ratio sample in $\mathrm{KBr}$ (Nicolet 60SXB). Simultaneous TG/DTA analysis of the crystalline phases were performed on an automatic derivatograph (Setaram TG-DTA 92). MAS NMR spectra were recorded in the solid state with a Broker DRX 500 spectrometer operating at a field of 11.7 Tesla. ${ }^{27} \mathrm{Al}$ spectra were recorded at a frequency of $130.3 \mathrm{MHz}$, with a pulse length of $2 \mu \mathrm{s}$ and a spinning speed of $3-5 \mathrm{KHz} .{ }^{31} \mathrm{P}$ spectra were recorded at a frequency of $202.45 \mathrm{MHz}$ with pulse length $1.5 \mu \mathrm{s}$ and the recycle delay is $4 \mathrm{~s}$. $1 M \mathrm{Al}\left(\mathrm{NO}_{3}\right)_{3}$ and $1 M \mathrm{H}_{3} \mathrm{PO}_{4}$ solutions (for aluminium and phosphorous) were used as standards.

\section{References}

1. D. W. Breck, "Zeolite Molecular Sieves : Structure, Chemistry and Use", Wiley, London, 1973.

2. R. M. Barrer, "Hydrothermal Chemistry of Zeolites", Academic Press, London, 1982.

3. S. T. Wilson, B. M. Lok, C. A. Messina, T. R. Cannon and E. M. Flanigen, J. Am. Chem. Soc., 1982, 104, 1146.

4. B. M. Lok, C. A. Messina, R. L. Patton, R. T. Gajek, T. R. Cannan and E. M. Flanigen, J. Am. Chem. Soc., 1984, 106, 6092.

5. J. B. Parise, J. Chem. Soc., Chem. Commun., 1985, 606.

6. G. Yang, S. Feng and R. Xu, J. Chem. Soc., Chem. Commun., 1987,1254

7. M. E. Davis, C. Saldarriage, C. Montes. J. Garces and C. Crowder, Nature, 1988, 331, 698.

8. M. Estermann, L. B. McCusker, C. Baerlocher, A. Merrouche and H. Kessler, Nature, 1991, 352, 320.

9. Q. Huo, R. Xu, S. Li, Z. Ma, J. M. Thomas, R. H. Jones and A. M. Chippindale, J. Chem. Soc., Chem. Commun., 1992, 875.

10. "Verified Synthesis of Zeolitic Materials", ed. H. Robson, Elsevier, Amsterdam, 2001.

11. R. Szostak. "Handbook of Molecular Sieves", Van Nostrand Reinhold, New York, 1992.

12. C. S. Blackwell and R. L. Paatton, J. Phys. Chem., 1988, 92, 3965.

13. M. E. Davis, C. Montes, P. E. Hathaway, J. P. Arhancet, D. L. Hasha and J. M. Garces, J. Am. Chem. Soc., 1989, 92. 3919. 